\title{
Lâminas de irrigação e sombreamento na produção de biomassa de Acariçoba (Hydrocotyle umbellata L.)
}

\author{
ALVES, N.M.1; LIMA, M.D.B.';PAULA, J.R. ${ }^{2} ;$ SIMON, G.A. ${ }^{1}$ \\ Universidade de Rio Verde, Campus Universitário, CEP 75901970 -Rio Verde-GO. nildaalves@fesurv.br; \\ ${ }_{2}^{2}$ Faculdade de Farmácia - UFG, CEP 74605 220-Goiânia - GO
}

\begin{abstract}
RESUMO: A acariçoba é uma planta utilizada pela medicina ayurvédica e em cosméticos por possuir propriedades rejuvenescedoras e revitalizante do sistema nervoso e cérebro. Com objetivo de avaliar os caracteres agronômicos e o teor de flavonóides totais de acariçoba em resposta a aplicação de lâminas distintas de irrigação e sombreamento, foi conduzido um experimento em área localizada nas coordenadas $17^{\circ} 47^{\prime} 53^{\prime \prime}$ latitude (S); longitude (W) $-51^{\circ}$ $55^{\prime} 53$ ", com altitude média de $648 \mathrm{~m}$, no período de julho a novembro. O clima é Aw (tropical), relevo suave ondulado ( $8 \%$ de declividade) com solo classificado como Latossolo Vermelho Distroférrico e textura argilosa. As temperaturas médias anuais são $18,1^{\circ} \mathrm{C}$ e $30^{\circ} \mathrm{C}$. A umidade relativa do ar média é de $64,7 \%$ e a precipitação total anual média é de $1550 \mathrm{~mm}$, com estações do ano seca e chuvosa, bem definidas. O ensaio foi conduzido em blocos casualizados em esquema fatorial $2 \times 2$, com 5 repetições totalizando vinte unidades experimentais com dois manejos de irrigação, sendo um com aplicação de uma lâmina de água diariamente, e outro, com duas aplicações de lâmina de água diariamente. Os tratamentos de sombreamento foram a pleno sol e com $50 \%$ de sombreamento. Foram avaliadas a massa fresca e massa seca das partes aéreas, a altura e o número de plantas, e o teor de flavonóides totais das partes aéreas. A produção de flavonóides foi favorecida pelo sombreamento, enquanto a irrigação não influenciou nem na produção de flavonoides, nem nos caracteres agronômicos avaliados.
\end{abstract}

Palavras chave: plantas medicinais, compostos fenólicos, flavonóides.

\begin{abstract}
Levels of irrigation and shade in the production of the biomass of dollarweed (Hydrocotyle umbellata L.). Dollarweed is a plant that is widely used by the Ayurvedic medicine and in the cosmetics industry because of its rejuvenating and revitalizing properties related to the nervous system and the brain. In order to evaluate the agronomic characteristics and the content of total flavonoids of the dollarweed, in response to the application of different levels of irrigation and shade, an experiment was conducted in an area at the coordinates $17^{\circ} 47^{\prime} 53^{\prime \prime}$ latitude (S), $51^{\circ} 55^{\prime} 53^{\prime \prime}$ longitude (W), with a mean altitude of $648 \mathrm{~m}$, from July to November. The climate is Aw (tropical), gently undulating relief ( $8 \%$ slope) with distroferric red latosol and clayey texture. The average annual temperatures are $18.1^{\circ} \mathrm{C}$ and $30^{\circ} \mathrm{C}$. The average relative humidity of the air is $64.7 \%$ and the average annual rainfall is $1550 \mathrm{~mm}$, with well-defined dry and rainy seasons. The assay was in randomized blocks, with a $2 \times 2$ factorial design, with 5 repetitions, amounting to twenty experimental units with two irrigation managements, being one with a daily application of water and the other with two daily applications of water. The shading treatments were under full sun and $50 \%$ shade. The fresh and dry weights of the aerial parts, the height and number of plants and the total content of flavonoids of the aerial parts were evaluated. The production of flavonoids was favored by the shade; irrigation did not influence the production of flavonoids or the agronomic characters evaluated.
\end{abstract}

Keywords: medicinal plants, phenolic compounds, flavonoids.

\section{INTRODUÇÃO}

Hydrocotile umbellata L., conhecida como acariçoba, pertence à família Apiaceae. De acordo com a medicina ayurvédica, é considerada rejuvenescedora e revitalizante do sistema nervoso e cérebro, com indicações também como suporte no tratamento de pacientes hipertensos por seu 
efeito ansiolítico e diurético e por sua ação tônica, é também indicado como complemento nos casos de anemia, emagrecimento, debilidade do sistema imunológico e sintomas de desgaste psicofísico, como envelhecimento precoce e queda de cabelos (Florentino et al., 2013).

Responsáveis por essas ações, acreditase são os compostos químicos presentes nas plantas, as quais sintetizam tais compostos à partir dos nutrientes, água e luz obtidos do ambiente. Estes compostos podem provocar reações nos organismos que resultam na ação terapêutica e são denominados de princípios ativos. Diversos fatores influenciam a qualidade dos compostos das plantas, tais como: variações climáticas, solo, época de colheita, características genéticas da planta, condições de secagem e tempo de armazenamento (Barbosa et al., 2006).

Fatores como disponibilidade de água, radiação solar, temperatura entre outros, podem alterar as propriedades medicinais de uma planta. Portanto faz-se necessário conhecer a influencia desses fatores para o uso correto e seguro das espécies. Se cultivada sob diferentes condições hídricas, as plantas podem apresentar alterações qualitativas e quantitativas no metabolismo secundário. Em condições de estresse hídrico, vários processos fisiológicos são alterados, tais como: fotossíntese, abertura estomática, produção de ácido abscísico, abscisão foliar e ajuste osmótico (Taiz \& Zeiger, 2004).

Bezerra Neto et al. (2005) relatam que em condições de manejo adequado de um dado cultivo é possível viabilizar benefícios que propiciem um maior rendimento na produção de plantas, exemplificando o uso de tela de polipropileno, que reduz a incidência direta dos raios solares, permitindo uma variação ótima de luminosidade e a elevação da fotossíntese. O uso de tais telas de sombreamento pode contribuir para a diminuição dos efeitos extremos de temperatura e luminosidades elevadas, sobre tudo a fotorrespiração e maior produtividade e qualidade das folhas (Beltrão \& Oliveira, 2008).

Pesquisas indicam que o crescimento em altura é uma das respostas mais características e rápidas ao sombreamento. As espécies que respondem ao sombreamento com maior crescimento em altura são capazes de escapar às alterações mais prejudiciais causadas pelo sombreamento, sendo este o caso da sálvia, tomilho e artemísia (Carvalho et al., 2006).

Um cultivo, mesmo que planejado, fica exposto às variações climáticas, especialmente em relação às chuvas. Dessa forma, o excesso hídrico pode proporcionar falta de oxigênio, o que prejudica a respiração e a assimilação dos fotoassimilados, assim como o déficit hídrico pode provocar o fechamento dos estômatos, diminuindo a divisão e o crescimento das células (Rego et al., 2004). Portanto, a irrigação é uma ferramenta importante na garantia do suprimento hídrico adequado à cultura nos momentos de maior demanda (Koutroubas et al., 1999). Dessa forma, a quantidade de água a ser aplicada também às espécies medicinais deve ser de acordo entre outras, com as propriedades físicas do solo.

A maximização na produção de princípios ativos é um dos objetivos quando se realiza um cultivo de determinada planta medicinal, provocando nesta um estresse, seja por meio da luminosidade, nutrição ou quantidades diferenciadas de água. No entanto, há que se considerar um comprometimento da produção de fitomassa, na maioria das vezes. É o que descreve Souza et al., (2007) ao observar a influência do sombreamento na produção de fitomassa e óleo essencial em alecrim-pimenta (Lippia sidoides Cham.).

Em virtude do potencial fitoterápico e das poucas informações sobre o desenvolvimento e cultivo de Hydrocotile umbellata L., objetivou-se com este estudo, avaliar a interferência de diferentes suprimentos de água, decorrentes da aplicação de distintas lâminas de irrigação e do sombreamento na produção de biomassa e do teor de flavonóides em plantas de acariçoba.

\section{MATERIAL E MÉTODOS}

O experimento foi conduzido em uma área experimental da Universidade de Rio Verde, localizado a $17^{\circ} 47^{\prime} 53^{\prime \prime}$ latitude (S); longitude (W) $-51^{\circ} 55^{\prime} 53^{\prime \prime}$, com altitude média de $648 \mathrm{~m}$, no período de julho a novembro de 2009. O clima conforme Köppen é classificado como Aw (tropical), relevo suave ondulado ( $8 \%$ de declividade), em solo classificado como Latossolo Vermelho Distroférrico com textura argilosa (Embrapa, 1999). As temperaturas médias anuais, mínima e máxima, são $18,1^{\circ} \mathrm{C}$ e $30^{\circ} \mathrm{C}$, respectivamente. A umidade relativa do ar média é $64,7 \%$ e a precipitação total anual média é de $1550 \mathrm{~mm}$, com estações do ano seca e chuvosa, bem definidas.

O ensaio foi instalado em blocos casualizados, em esquema fatorial $2 \times 2$, com 5 repetições totalizando vinte unidades experimentais. Cada parcela foi constituída por 4 linhas de plantio, espaçadas de $20,0 \mathrm{~cm}$ entre si e comprimento de 2 $\mathrm{m}$. Foi considerada área útil as duas fileiras centrais. Foram testados dois manejos de irrigação, sendo um com aplicação de uma lâmina de água diariamente e outro com duas aplicações de lâmina de água diariamente, e os tratamentos de sombreamento foram pleno sol e $50 \%$ de sombreamento.

As mudas iniciais foram obtidas no Horto

Rev. Bras. PI. Med., Campinas, v.17, n.2, p.210-214, 2015. 
de Plantas Medicinais da Faculdade de Farmácia da UFG, identificadas pelo Prof. José Realino de Paula. Uma exsicata foi depositada no Herbário da Universidade Federal de Goiás com número UFG22394. Objetivando padronizar o tamanho e vigor das plantas, as mudas foram transplantadas para o horto de plantas medicinais da Universidade de Rio Verde - UniRV, em tubetes, usando-se substrato comercial. As mudas foram irrigadas diariamente, por meio de microaspersores. Estas foram transplantadas quando se constatou o pegamento das mesmas, o que ocorreu 4 semanas depois. Amostras de solo, de $0-20 \mathrm{~cm}$ de profundidade, foram coletadas para realizar a análise química e física (Tabela 1). A correção da acidez do solo foi feita de forma a elevar a saturação em bases a $70 \%$, sendo realizada 30 dias antes do plantio, utilizando-se para tanto, 92,6 $\mathrm{g} / \mathrm{m}^{2}$ de calcário dolomítico, conforme Lopes et al. (1991). Para o preparo do solo foi feita uma aração e em seguida foram confeccionados manualmente os canteiros de 2,0 m de comprimento, $1,0 \mathrm{~m}$ de largura e 20,0 cm de altura.

$\mathrm{Na}$ adubação de plantio aplicou-se $2,5 \mathrm{l} / \mathrm{m}^{2}$ de esterco de aves curtido. A área total experimental foi de $400,0 \mathrm{~m}^{2}$. Os tratamentos de irrigação testados foram representados pelos manejos adotados: T1 turno de irrigação pela manhã as 8:00 horas, com a lâmina de irrigação em conformidade com a disponibilidade hídrica do solo. T2 tratamento com irrigações efetuadas diariamente as 8:00 e 16:00 horas, utilizou-se para ambos tratamentos, regador graduado, distribuindo uniformemente a lâmina correspondente por toda a parcela. Esta foi calculada em função da curva característica de umidade do solo da área, determinada previamente, em que: Capacidade de campo $=23,7 \%$ e a umidade crítica $=21 \%$. Considerando-se a profundidade do sistema radicular a $20 \mathrm{~cm}$, lâmina líquida a aplicar por irrigação foi:

$$
\begin{aligned}
& \mathrm{LL}=(\mathrm{CC}-\mathrm{UC}) \times \mathrm{Z} \\
& \mathrm{LL}=(0,237-0,21) \times 20 \\
& \mathrm{LL}=0,54 \mathrm{~cm}=5,4 \mathrm{~mm}=5,5 \mathrm{~L} / \mathrm{m}^{2} \\
& \text { Ou } 11,0 \mathrm{~L} / \text { canteiro }
\end{aligned}
$$

Os tratamentos de luminosidade testados foram: $0 \%$ de sombreamento (onde as mudas ficaram expostas ao sol pleno) e $50 \%$ de luminosidade (sombreamento). Esse último foi obtido com o uso de telas de poliolefinas, que recobriam a parte superior de um túnel com dimensões de $5 \mathrm{~m} \times 20$ $\mathrm{m}$ e $0,70 \mathrm{~m}$ de altura. Cada tratamento recebeu 36 mudas, as quais foram cultivadas, nestas condições, desde a semeadura. Aos 90 dias após o plantio foram avaliados os caracteres agronômicos como altura das plantas, medida com o auxílio de fita métrica, a massa fresca da parte aérea, obtido por meio da média das folhas e caules das plantas de cada parcela útil, expresso em g/parcela, usandose balança semi-analítica, o número de plantas por parcelas e a massa seca da parte aérea. Imediatamente após a colheita das plantas de cada parcela útil, foi feita a pesagem destas para a obtenção da massa fresca.

Para a obtenção da massa seca das partes aérea, após a colheita das plantas e a pesagem da massa fresca, as mesmas permaneceram em torno de 7 dias em estufa de circulação de ar forçado, com temperatura de $40^{\circ} \mathrm{C}$, para a perda do excesso de umidade, após peso constante, foram novamente pesadas obtendo assim o peso seco. Após a secagem, as amostras foram moídas em moinho do tipo Willey, com peneira de $1 \mathrm{~mm}$, e armazenadas em sacos de plástico, para posterior doseamento.

A determinação dos teores de flavonóides totais presentes nas partes aéreas de $H$. umbellata $L$., foi realizada a partir de amostras secas das partes aéreas das plantas de cada parcela, em uma solução metanólica. Foi utilizado o método espectrofotométrico descrito por Rolim et al. (2005) modificado. Esta técnica baseia-se na propriedade dos flavonóides em absorver radiação no comprimento de onda da luz ultravioleta (UV) de forma proporcional a sua concentração. Foi utilizado a Rutina (3-O-rutinosídeo-quercetina), um flavonol O-heterosídeo como padrão. A solução metanólica $(0,5 \mathrm{~g})$ foi dissolvida em $100 \mathrm{ml}$ da solução de metanol:ácido acético 0,02M (99:1), aquecida em banho-maria sob refluxo a $90-100^{\circ} \mathrm{C}$ por 40 minutos e filtrada. Após resfriamento, a absorbância das amostras foi medida a $361 \mathrm{~nm}$ utilizando-se cubetas de quartzo, tendo como "branco" o metanol e todos os reagentes, menos o extrato. O teor de flavonóides totais foi determinado por interpolação da absorbância das amostras contra uma curva de calibração construída com padrões de rutina (10 $\mathrm{mg} / 100 \mathrm{ml}$ ) e expressos como $\mathrm{mg}$ de equivalentes de rutina por $\mathrm{g}$ de extrato.

\begin{tabular}{|c|c|c|c|c|c|c|c|c|c|c|c|}
\hline $\mathrm{pH}$ & $\mathrm{Ca}$ & $\mathrm{K}$ & $\mathrm{Mg}$ & $\mathrm{Al}$ & $\mathrm{H}+\mathrm{Al}$ & K & P(Mellich) & M.O. & Argila & Silte & Areia \\
\hline \multicolumn{12}{|c|}{$\mathrm{Mg}$} \\
\hline agua & \multicolumn{2}{|c|}{$\mathrm{cmol}_{\mathrm{c}} \mathrm{dm}^{-3}$} & & & & $\mathrm{dm}$ & $\mathrm{g} \mathrm{kg}^{-1}$ & & $\mathrm{~g} \mathrm{~kg}^{-1}$ & & \\
\hline 4,4 & 1,36 & 0,28 & 0,73 & 0,45 & 4,8 & 65 & 2,07 & 21,67 & 600 & 50 & 350 \\
\hline
\end{tabular}

As concentrações de flavonóides totais nas amostras foram calculadas utilizando a equação de

TABELA 1. Caracterização química e textural do solo na camada de $0-20 \mathrm{~cm}$.

Rev. Bras. PI. Med., Campinas, v.17, n.2, p.210-214, 2015. 
regressão linear da curva de calibração, $R=0,9998$, apresentada abaixo:

$$
\text { Concentração }=\frac{\text { Absorbância }-0,0263}{13,71}
$$

A partir da concentração, calculou-se a percentagem (\%) de flavonóides totais de acordo com a expressão abaixo:

$$
\% \text { flavonóides }=\frac{x(\mathrm{mg}) \cdot 100 \cdot 10^{-3} \cdot 10^{2}}{\mathrm{~m}(\mathrm{~g})}
$$

Onde:

100 = fator de diluição da amostra.

$\mathrm{x}=$ concentração em $\mathrm{mg} / \mathrm{ml}$, obtida pela curva padrão com a Absorbância da amostra;

$\mathrm{m}=$ massa da amostra em grama .

Os dados foram submetidas a análise de variância e as médias comparadas pelo teste de comparação de Tukey a $5 \%$ de probabilidade utilizando o software GENES (Cruz, 2001).

\section{RESULTADOS E DISCUSSÃO}

O manejo da irrigação com um ou dois turnos diários de rega, não interferiram significativamente em nenhum dos caracteres agronômicos avaliados (Tabela 2). As médias de massa fresca da parte aérea a massa seca da parte aérea, o número de plantas e a altura das plantas, não diferiram significativamente entre si em relação a variação na luminosidade.

Pouco se sabe sobre o efeito da água sobre a formação de compostos fenólicos na planta, entre eles, os flavonóides. Bortolo et al., (2009) avaliaram o teor e rendimento de flavonóides em calêndula (Calendula officinalis L.) cultivada com diferentes lâminas de irrigação, e verificaram que as mesmas não interferiram nos teores de flavonóides. Resultados semelhantes foram obtidos por Pacheco (2007), nos quais não verificaram diferença significativa entre intensidades de deficiências hídricas testadas (representadas por intervalos de interrupção da irrigação) e o tratamento controle (plantas irrigadas) com relação ao teor de flavonóides totais em inflorescências de calêndula.

Esses resultados são contraditórios com os encontrados por outros pesquisadores, os quais comprovaram a influencia da disponibilidade hídrica na biomassa de espécies medicinais. Cita-se entre eles, Costa Filho et al. (2006), avaliando a influência hídrica e térmica no crescimento e desenvolvimento de Ocimum gratissimum L., verificaram que a massa fresca da parte aérea foi significativamente maior naqueles indivíduos com maior suprimento hídrico. Segundo Carvalho et al. (2005), a diminuição na disponibilidade hídrica do substrato reduziu o teor de partenolídeo em plantas de artemísia (Tanacetum parthenium L.).

TABELA 2. Análise da variância para teor de flavonóides (FLA), massa fresca da parte aérea (MFPA), massa seca da parte aérea (MSPA), altura da planta (AP) e número de plantas (NP) avaliadas em produção de acariçoba, sob a aplicação de lâminas distintas de irrigação e sombreamento.

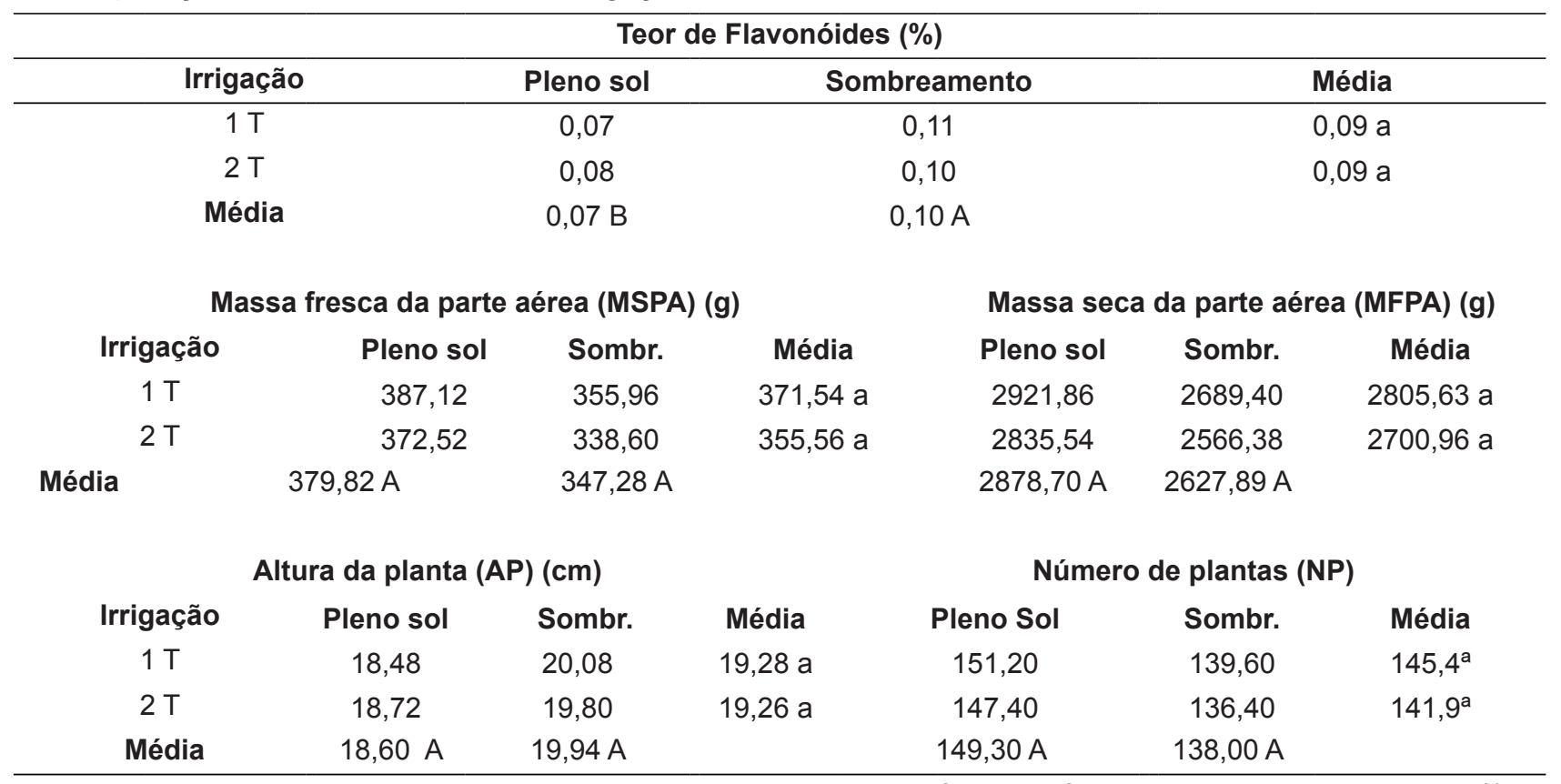

Médias seguidas de mesma letra maiúscula na linha e minúscula na coluna, não diferem significativamente pelo teste de Tukey a $5 \%$. 
O estímulo no crescimento em altura é uma das respostas mais características ao sombreamento. A priori, as plantas são capazes de evitar ou suportar o sombreamento. As espécies que respondem ao sombreamento com maior crescimento em altura são capazes de escapar às alterações mais prejudiciais causadas pelo sombreamento (Taiz \& Zeiger, 1998; Morelli \& Ruberti, 2000). Os resultados aqui obtidos para as variáveis agronômicas, massa fresca da parte aérea, massa seca da parte aérea, número de plantas e a altura de plantas para as plantas mantidas em sombreamento em comparação as plantas mantidas a sol pleno, também se mostraram estatisticamente iguais. No entanto o teor de flavonóides de acariçoba foi superior quando desenvolvido em sombreamento, em comparação ao desenvolvido a sol pleno, denotando um efeito positivo da baixa irradiância na síntese deste grupo de metabólito secundário (Tabela 2).

Os resultados apresentados neste trabalho permitiram concluir que o sombreamento favoreceu a produção de flavonóides em Hydrocotyle umbellata, não tendo este tratamento influência nos demais caracteres agronômicos. A acariçoba não respondeu aos diferentes suprimentos de água no solo, ou seja, a irrigação não influenciou a produção de flavonóides e nem os caracteres agronômicos avaliados.

\section{REFERÊNCIAS}

BARBOSA, F.F.; BARBOSA, L.C.A.; MELO, E.C.; BOTELHO, F.M.; SANTOS, R.H.S. Influência da Temperatura do Ar de Secagem Sobre o Teor e a Composição Química do Óleo Essencial de lippia alba (mill) N. E. Brown. Revista Química Nova, vol.29, n.6, p.1221-1225, 2006.

BELTRÃO, N.E.M.; OLIVEIRA, I.P.O. Produção de energia produtividade: Ricinus communis L. X Saccharum officinale L. In: III Congresso Brasileiro de Mamona, 2008, Salvador. III Congresso Brasileiro de Mamona, 2008.

BEZERRA NETO, F.; ROCHA, R.C.C.; NEGREIROS, M.Z.; ROCHA, R.H.; QUEIROGA, R.C.F. Produtividade de alface em função de condições desombreamento e temperatura e luminosidade elevadas. Horticultura Brasileira, Brasília, v. 23, n. 2, p. 189-192, 2005.

BORTOLO, D.P.G.; MARQUES, P.A.A.; PACHECO, A.C. Teor e rendimento de flavonóides em calêndula (Calendula officinalis L.) cultivada com diferentes lâminas de irrigação. Revista brasileira de plantas medicinais, Botucatu, v.11, n.4, p.435-441, 2009.

CARVALHO, L.M.; CASALI, V.W.D.; SOUZA, M.A.; BARBOSA, L.C.A.; CECON, P.R. Crescimento, teor de partenolídeo e de prolina em plantas de Tanacetum parthenium (L.) Schultz-Bip crescidas em substrato com diferentes teores de umidade. Acta Scientiarum - Agronomy, v.27, n.1, p.151-157 Jan./March, 2005.
CARVALHO, L.M.; CASALI, V.W.; LISBOA, S.P.; BARBOSA, L.C.A.; CECON, P.R. Crescimento e metabolismo em artemísia em função do nível de irradiância. Horticultura brasileira, v. 24, n. 3, jul.-set. 2006.

COSTA FILHO, L.O.; ENCARNAÇÃO, C.R.F.; OLIVEIRA, A. F. M. Influência hídrica e térmica no crescimento e desenvolvimento de Ocimum gratissimum L. Revista brasileira de plantas medicinais, Botucatu, v.8, n.2, p.8-13, 2006.

CRUZ, C.D., Programa Genes. Versão Windows. Viçosa: universidade Federal de Viçosa, 2001. 648p.

EMPRESABRASILEIRADE PESQUISAAGROPECUÁRIA. Sistema brasileiro de classificação do solo. Brasilia, 412 p. 1999.

FLORENTINO, I.F.; NASCIMENTO, M.V.M.; GALDINO, P.M.; BRITO, A. F.; ROCHA, F.F.; TONUSSI, C.R.; LIMA, T.C.M.; PAULA, J.R.; COSTA, E.A. Evaluation of analgesic and anti-inflammatory activities of Hydrocotyle umbellata L., Araliaceae (acariçoba) in mice, Anais da Academia Brasileira de Ciências, São Paulo, v.85, n.3, p. 987-997, 2013.

KOUTROUBAS, S.D.; PAPAKOSTA, D.K.; DOITSINIS, A. Adaptation and yielding ability of castor plant (Ricinus communis L.) genotypes in a Mediterranean climate. European Journal of Agronomy, v. 11, n. 3-4, p. 227-237, 1999.

LOPES, A.S.; SILVA, M.C.; GUILHERME, L.R.G. Acidez do solo e calagem. São Paulo: Associação Nacional para Difusão de Adubos e Corretivos Agrícolas. 1991. 15 p. Boletim Técnico; n.1.

MARTINS, R.E. et al. Plantas medicinais. 2. ed. Viçosa: UFV, 1998.

MORELLI, G; RUBERTI, I. Shade avoidance responses. Driving auxin along lateral routes. Plant Physiology. v.122, p. 621-626, 2000.

PACHECO, A.C. Deficiência hídrica e aplicação de ABA sobre as trocas gasosas e o acúmulo de flavonóides em calêndula (Calendula officinalis L.). 2007. 61p. Tese (Doutorado em Fisiologia e Bioquímica de Plantas) Universidade de São Paulo, Piracicaba.

REGO, J.L.; VIANA, T. V. A.; AZEVEDO, B. M.; BASTOS, F.G.C.; GONDIM, R.S. Efeitos de lâminas de irrigação sobre a cultura do crisântemo. Revista Ciência Agronômica, v.35, n.2, p.302-308. 2004.

ROLIM, A.; MACIEL, C. P. M.; KANEKO, T. M.; CONSIGLIERI, V. O.; SALGADO-SANTOS, I. M. N.; VELASCO, M. V. R. Validation assay for total flavonoids, as rutin equivalents, from Trichilia catiguá Adr. Juss (Meliaceae) and Ptychopetalum olacoides Bentham (Olacaceae) commercial extract. Journal Of AOAC International. v. 88, n.4, p 1015-1019. 2005.

SOUZA, M. F.; GOMES, ISMAI, P.A.; SOUZA JUNIOR,T.; FONSECA, M.M.; SIQUEIRA, C.S.; FIGUEIREDO, L.S.; MARTINS,E.R. Influência do Sombreamento na Produção de Fitomassa e Óleo Essencial em Alecrimpimenta (Lippia sidoides Cham.) Revista Brasileira de Biociências, Porto Alegre, v. 5, supl. 2, p. 108-110, jul. 2007.

TAIZ, L.; ZEIGER, E. Plant physiology. 2.ed. Sunderland: Sinauer Associates, 1998. 792p.

TAIZ, L.; ZEIGER, E. Fisiologia vegetal. 3.ed. Porto Alegre: Art med, 2004. 719p.

Rev. Bras. PI. Med., Campinas, v.17, n.2, p.210-214, 2015. 